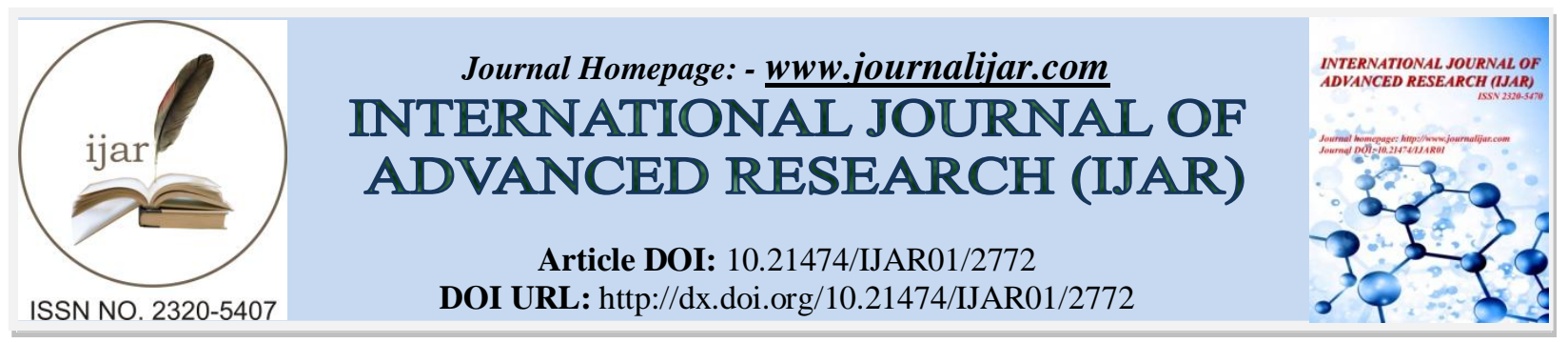

RESEARCH ARTICLE

\title{
ROLE OF SPIRITUAL AND RELIGIOUS PRACTICES IN MODERN MEDICAL THERAPY
}

Dr. Richik Tripathi.

BDS, MDS(Oral \& maxillofacial surgery), PhD Scholar faculty of dental sciences , IMS, BHU, VARANASI , INDIA, 221005.

\section{Manuscript Info \\ Abstract}

\section{Manuscript History}

Received: 15 November 2016

Final Accepted: 17 December 2016

Published: January 2017
Since ancient times spiritual and religious practices proved their worth in management of many disorders. In fact, religious and spiritual leaders were once strongly against the practice of modern medicine. As the time passed modern medicine laid firm foundation in human civilization and people slowly forgot about spiritual and religious practices. Few physicians and surgeons noticed great improvement in patients who were practicing spiritual and religious practices. Further studies aimed to find effect of religious and spiritual practices in diseased patients proved that, religious and spiritual practices in combination with modern medical therapy work synergistically and a high number of patients were cured in due time. This paper highlights the role of spiritual and religious practices in modern medical therapy.

Copy Right, IJAR, 2016,. All rights reserved.

Spiritual and religious practices are important aspects of medical care. However physicians are not sure about, when and how to address about religious issues. Physicians who spent a lot of time in reading modern medicine have little or no knowledge about religious or spiritual healing. There is an ethical issue in practicing spiritual healing according to which, a physician should not try to impose his or her belief on their patients. Apart from ethical issues as the modern medicine is being more directed towards science and technology physicians find it difficult to concentrate themselves on religion or spiritual healing. There are innumerable example in history where spiritual and religious healing proved to be successful. However, the question remains unanswered that, how spiritual or religious healing works or what is the exact science behind the spiritual healing. According to ancient literature spiritual and religious practices helps to initiate and regulate biofeedback mechanism. Yoga and Meditation are claimed to regulate secretion from pineal and pituitary glands ${ }^{1}$. If we combine the role of meditation and other spiritual practices we can find that these can have important role in prevention and management of various diseases related to cardiovascular, nervous, immune and reproductive system. various studies ${ }^{2,3}$ have found positive effect of yoga and meditation on nervous and cardiovascular system. As written in history books that, many saints possessed the power of healing as they eliminated illness in human using some supernatural power. Mother Teresa of Kolkata, India recently given the honor of being a saint as she has said to have healed an ailing patient through her prayers and supernatural power. The reality behind supernatural power is beyond the reach of science or beyond the imagination of human mind, as said by great saints and scholars of Hindu mythology.

Sometimes the physician or the patient is not religious and there is lack of understanding in between patient and physician. In this condition one must not try to impose his belief over another. Imposing the beliefs can have negative impact both upon the treatment and on the interpersonal relationship. Various researches which were focused on quality of life of patients having spiritual or religious beliefs have found that, overall quality of life of 
patients suffering from psychiatric and stress disorders is better than those not practicing spiritual or religious practices $^{4,5}$. Similarly few other studies in patients having cardiovascular disorders found that, spiritual and religious practices have profound effect on maintaining optimal health of cardiovascular system ${ }^{6,7}$. It was found that meditation has very critical role in maintaining good blood pressure in hypertensive and stressed patients. These finding again point towards possible effect of meditation and spiritual practices on pituitary, pineal glands and on the cardiovascular system. Apart from these disorders there are numerous infective, metabolic, inflammatory and neoplastic disorders which cannot be treated by using spiritual and religious practices. However if knowledge of spiritual practices is applied accurately, this can be used as an aid to reinforce patient to take proper medicine at right interval and for longer duration. Simkin. $\mathrm{P}$ et al in $2004^{8}$ published an update over non pharmacological method of labor pain control in which he focused on possible role of spiritual and religious practices to control labor pain. In fact spiritual practices are ancient method of labor pain control for generations till the analgesics and anesthesia were discovered. According to him, spiritual and religious belief help overcome maternal stress and other psychological problems related to premature delivery, abortion or infant death ${ }^{9}$.

In cancer patients receiving palliative therapy to extend life expectancy and in those cancer patients whose death is near spiritual practices again prove their worth. Most patients who were found have practicing the religious practices have fewer treatment related complaints or complications than those who were not practicing ${ }^{10}$. A study which was performed on female patients who were getting treatment for breast cancer, it was found that, those women practicing spiritual and religious practices had better immune response ${ }^{11}$.

\section{Conclusion:-}

Spirituality and religious practices are very strong tool in modifying body hormonal response and functioning of central nervous system. Together with modern medicine many psychological, psychiatric and cardiovascular diseases can be managed efficiently.

\section{References:-}

1. Yoga in relation to brain, pituitary - adrenocortical axis. In Interaction Within the Brain - Pituitary Adrenocortical Systems, Udupa, K.N. \& Singh R.H. (Ed. M.T.Jones, B.Gillham, M.F.Dallman, S.Chattopadhya). New York: Academic Press 1978

2. The effect of yogasanas on muscular tone and cardiovascular adjustment. Gopal Yoga Life, 1975. 6; 5:3-11

3. Muscle activity in some asans, a pilot study. P.V., Bhole, M.V. \& Gharote, M.L yog mimansa. 1969; $1: 1-13$

4. Religiousness affects mental health, pain and quality of life in older people in an outpatient rehabilitation setting. Lucchetti G, Lucchetti AG, Badan-Neto AM, Peres PT, Peres MF, Moreira-Almeida A, et al J Rehabil Med. 2011;43:316-22

5. Contribution of spirituality to quality of life in patients with residual schizophrenia. Shah R, Kulhara P, Grover S, Kumar S, Malhotra R, Tyagi S Psychiatry Res. 2011;190:200-5

6. Spirituality predicts health and cardiovascular responses to stress in young adult women. Edmondson, K. A., Lawler, K. A., Jobe, R. L., Younger, J. W., Piferi, R. L., \& Jones, W. H. Journal of Religion and Health,2005; 44(2): 161-171.

7. Review of the effect of spiritual and religious factors on mortality and morbidity with a focus on cardiovascular and pulmonary disease. Luskin, F. Journal of Cardiopulmonary Rehabilitation and Prevention, $2000 ; 20(1): 8$ 15.

8. Update on nonpharmacologic approaches to relieve labor pain and prevent suffering. Simkin, P., \& Bolding, A Journal of midwifery \& women's health, 2004; 49(6): 489-504.

9. Territories of the self and spiritual practices during childbirth. Birth Territory and Midwifery Guardianship: Parratt, J. Theory for practice, education and research Edinburgh: Butterworth Heinemann Elsevier, 2008: 3954.

10. Effect of spiritual well-being on end-of-life despair in terminally-ill cancer patients. McClain, C. S., Rosenfeld, B., \& Breitbart, W. The lancet, 2003; 361(9369):1603-1607.

11. Spiritual expression and immune status in women with metastatic breast cancer: an exploratory study. Sephton, S. E., Koopman, C., Schaal, M., Thoresen, C., \& Spiegel, D The breast journal, 2001; 7(5): 345-353. 